\section{NOVA TELLVS}

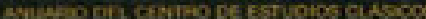

Nova Tellus

ISSN: 0185-3058

novatelu@servidor.unam.mx

Centro de Estudios Clásicos

México

Valdés García, María Alejandra

El relato y su posible argumentación según los tratadistas griegos de Ejercicios preparatorios

Nova Tellus, vol. 29, núm. 1, 2011, pp. 75-100

Centro de Estudios Clásicos

Distrito Federal, México

Disponible en: http://www.redalyc.org/articulo.oa?id=59121302004

Cómo citar el artículo

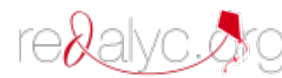

- Número completo

- Más información del artículo

Página de la revista en redalyc.org

Sistema de Información Científica

Red de Revistas Científicas de América Latina, el Caribe, España y Portugal

Proyecto académico sin fines de lucro, desarrollado bajo la iniciativa de acceso abierto 


\title{
El relato y su posible argumentación según los tratadistas griegos de Ejercicios preparatorios ${ }^{1}$
}

\author{
María Alejandra VALDÉs GARCíA \\ Universidad Nacional Autónoma de México \\ Facultad de Filosoía y Letras \\ malva.00@gmail.com
}

Resumen: En los Progymnásmata el ejercicio escolar denominado relato es susceptible de refutación o confirmación mediante los "principios de argumentación finales". La refutación del relato puede elaborarse a partir de los siguientes tópicos: oscuridad, inverosimilitud, inutilidad, inadecuación, redundancia, novedad, etcétera, y puede confirmarse a partir de los opuestos correspondientes. También se obtiene abundancia de lugares de argumentación si ésta se basa en los llamados "elementos básicos" en los que se fundamenta la acción: personaje, hecho, lugar, tiempo, modo, causa e instrumento.

\section{Possible lines of argument in the account according to the Greek authors of Progymnásmata}

Abstract: At Progymnásmata the school exercise called diegema is capable of refutatio or confirmatio by the so called telika kephalaia. The refutation can be done from the following topoi: obscurity, unlikeliness, uselessness, inadequation, redundancy, innovation, etc., and it can be confirmed from the opposite topics. It also can get arguments from loci if the argumentation is done from the stoicheia diegematos in which the action is based: prosopon, pragma, topos, chronos, tropos, aitia and hyle.

PALABRAS CLAVE: Relato, narración, argumentación, progymnásmata, lugares de argumentación. KEYWORDS: Account, line of argument, progymnásmata.

RECEPCIÓN: 14 de octubre de 2010.

ACEPTACIÓN: 20 DE ENERO DE 2011.

\footnotetext{
${ }^{1}$ Comunicación presentada en el Segundo Coloquio Internacional de Retórica: "La argumentación en la retórica: escuelas y perspectivas“, UNAM-FFyL, 25 a 27 de marzo de 2009. Su publicación se lleva a cabo dentro del proyecto de investigación de La retórica escolar: su incidencia en los papiros, su influencia en la literatura y sus modelos literarios (FFI2010-21125, subprograma FILOS, financiado por el MICINN).
} 



\title{
El relato y su posible argumentación según los tratadistas griegos de Ejercicios preparatorios
}

\author{
María Alejandra VALDÉS GARCíA
}

El relato $(\delta i n ́ \gamma \eta \mu \alpha)$ como ejercicio retórico está comprendido en los manuales de Progymnásmata o Ejercicios preparatorios. ${ }^{2}$ Es, entre los ejercicios escolares, uno de los más sencillos, según palabras del rétor Nicolás de Mira, ${ }^{3}$ puesto que no se trata de una hipótesis sencilla, sino solo de una parte de ella, y por lo tanto no se basta solo; ${ }^{4}$ es sencillo, ciertamente, si uno se centra en la teoría del relato de los tratadistas griegos Hermógenes, Aftonio y Nicolás, pero, innegablemente, esta apreciación cambia al leer el manual de Teón de Alejandría que contiene una prolija teoría del relato, cuya razón obedece a que funge como introducción del resto del manual de ejercicios preparatorios. Esto puede apreciarse a lo largo del desarrollo de su obra, en la que constantemente remite al ejercicio del relato, debido a que debían dominarse los aspectos argumentativos que en este progýmnasma trata largamente. El objetivo de esta exposición es dar al lector interesado en el tema la teoría básica del relato contenida en los autores más conocidos de Progymnásmata.

\section{Definición}

La definición de relato es muy semejante en todos los tratadistas: "Un relato es una composición expositiva de hechos que han sucedido o que se admiten como sucedidos". 5

${ }^{2}$ Las ediciones utilizadas para estos rétores son: M. Patillon-G. Bolognesi (eds.), Aelius Theo, Progymnasmata, Paris, Belles Lettres, 1997; H. Rabe (ed.), Hermogenes. Progymnasmata, Rhetores Graeci ( $R G)$, vol. 6, Lipsiae, Teubner, 1913; H. Rabe (ed.), Aphthonius. Progymnasmata, RG, vol. 10, Lipsiae, Teubner, 1926; I. Felten (ed.), Nicolaus. Progymnasmata, RG, vol. 11, Lipsiae, Teubner, 1913; R. Foerster (ed.), Libanius. Progymnasmata, Opera, vol. 8, Lipsiae, Teubner, 1915. Sobre el ejercicio del relato cf. Theo., 78-96; Hermog., Prog., 4-6; Aphth., 2-3; Nicol., 11-17; Lib., Prog., 29-58.

${ }^{3} \mathrm{Nicol}, 11$.

${ }^{4}$ Id. 17.

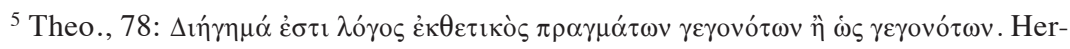

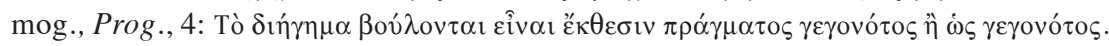


Teón de Alejandría desarrolla la teoría del relato de manera más completa y detallada que Hermógenes de Tarso o Aftonio de Antioquía, proporcionando todas las indicaciones pormenorizadas para el desarrollo de

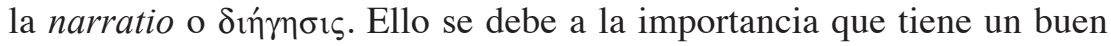
conocimiento de las circunstancias en cualquier tipo de discurso oral o escrito, especialmente si se trata de un discurso judicial. ${ }^{6}$

\section{Denominación}

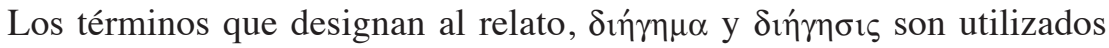
de manera indiferente en algunos de los manuales. Para Teón, que nunca los diferencia, relato $(\delta ı \eta ́ \gamma \eta \mu \alpha)$ y narración ( $\delta ı \eta ́ \gamma \eta \sigma ı \varsigma)$ son una misma cosa; y en ello concuerda Nicolás, puesto que se refiere a $\delta ı ́ \gamma \eta \mu \alpha$ en el sentido ya de relato, cuando se usa en la argumentación, en el exemplum $^{7}$ o en el epílogo, ya de narración, cuando se habla de narratio, la parte central del discurso. En sus palabras:

La narración ( $\delta ı ́ r \eta n \mu \alpha)$ nos ejercita por igual en todos los géneros del discurso, me refiero al deliberativo, judicial y panegírico, pues en todos necesitamos

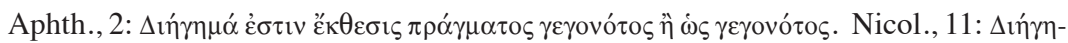

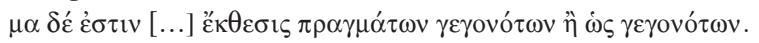

Cito la traducción de M. D. Reche, Teón, Hermógenes, Aftonio. Ejercicios de retórica, Madrid, Gredos (BCG 158), 1991 para estos tres autores. Las de Nicolás son propias.

Libanio no proporciona una exposición sistemática como los demás tratadistas, sino que de los ejemplos proporcionados hay que inferir la teoría. Es interesante la apreciación que respecto a esto hace Schouler, a diferencia de los ejemplos de Aftonio que no salen del esquema propio de las obras técnicas; Libanio presenta piezas que son, más que un simple ejemplo, un modelo acabado, cf. Schouler, La tradition hellénique chez Libanios, Paris, Belles Lettres, 1984, vol. 1, p. 56.

${ }^{6}$ El discurso judicial equivale al género civil o privado, dentro de la enumeración de géneros del relato que hace Hermog., Prog., 4.

${ }^{7}$ El relato suele estar presente en el exemplum, como ya ha dicho Nicol., 16, así como la comparación y la chreia (cf. Auct., ad Her., 4, 49, 62). La definición de relato que dan los rétores griegos es muy similar a la que da Quintiliano para exemplum, con la diferencia de que narratio es expositio $(4,2,3)$ y exemplum es commemoratio $(5,11,6)$ de un hecho real o presuntamente real. Sobre la elaboración del exemplum dissimile o contrarium, Quint., $5,11,13$ alude a todos los elementos del relato. La comparación como exemplum puede ser simile, maius minoris o minus maioris. La chreia es tenida como exemplum bajo el concepto de anécdota, donde entran también elementos del relato. Acerca de exemplum y narración, cf. Aragüés Aldaz, 1997, pp. 415-434 y Guerrini, 1980, pp. 77-96. 
de ella. Incluso, como el discurso político está dividido en cinco partes,

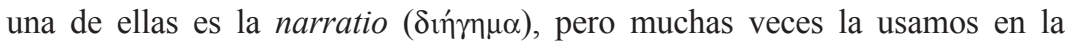
argumentación y especialmente en las pruebas que sirven de ejemplo y aun en los epílogos, cuando recordamos lo que se ha dicho. ${ }^{8}$

Sin embargo, el mismo Nicolás, más adelante, establece la diferencia entre ambos términos: el relato incluiría un único hecho, mientras que la narración, varios. ${ }^{9}$ En los Progymnásmata de Hermógenes y Aftonio ambos términos aparecen perfectamente diferenciados y delimitados; por ello, en sus tratados la exposición de este ejercicio varía poco y es más sencilla:

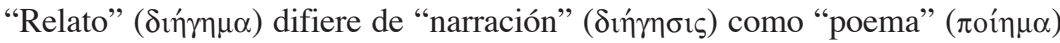

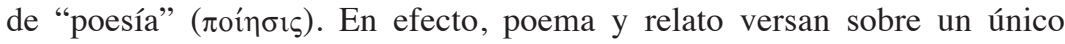
hecho; poesía y narración sobre más, por ejemplo: poesía es la Ilíada y poesía es la Odisea, mientras que poemas son la fabricación del escudo, la evocación de los muertos y la matanza de los pretendientes. Y, a su vez, una narración es la Historia de Heródoto y la obra de Tucídides, mientras que un relato es el episodio de Arión y el de Alcmeón. ${ }^{10}$

De cualquier manera, la función y el propósito de ambos es la misma: proporcionar al oyente la exposición y explicación, ya sea de un hecho, ya sea de muchos. ${ }^{11}$

Dentro de la teoría retórica latina, en la Retórica a Herenio y en el De inventione de Cicerón encontramos enumeradas tres clases de narraciones: la primera, en la que se narran los hechos con los aspectos favorables al caso si hay por medio una sentencia; la segunda, que sirve para acusar, para comparar, como digresión o para amplificar; y la tercera, que no se usa en los procesos legales y que simplemente corresponde a una situación, siendo así un ejercicio útil para expresarse correctamente de manera oral o escrita, y es, por lo tanto, a esta tercera clase a la que pertenecen los relatos literarios. ${ }^{12}$

\footnotetext{
${ }^{8}$ Nicol., 15-16. También aparece el relato en el proemio, donde se anuncia brevemente el asunto (i $\pi$ ó $\theta \varepsilon \sigma i \varsigma)$ que va a desarrollarse de manera completa en la narratio. Para su inclusión en el proemio, cf. Quint., 4, 1, 31 y 52; para su inclusión en el epílogo, cf. Ibid., 6, 1, 15.

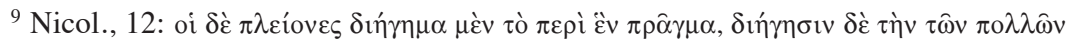

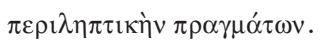

${ }^{10}$ Hermog., Prog., 4; para reflexiones semejantes cf. Aphth., 2, Nicol., 12.

${ }^{11}$ Nicol., 4.

${ }^{12}$ Auct. ad Her., 1, 8, 12; Cic., Inv., 1, 19, 27.
} 


\section{Elementos del relato}

El relato es la forma básica del discurso y consta de seis elementos ( $\sigma \tau \iota \chi \varepsilon i \hat{\alpha} \alpha)$ : personaje(s), hecho(s), tiempo, lugar, modo y causa. ${ }^{13}$ Nicolás advierte que puede añadirse un séptimo: el instrumento. ${ }^{14}$ Se considera

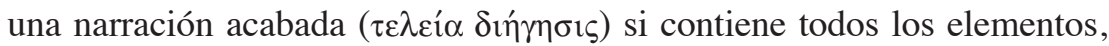

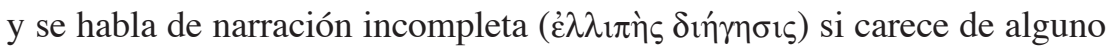
de ellos. ${ }^{15}$ Esta última es muy frecuente, pues lo más importante del relato es el hecho o los hechos, y si no importan o ya se conocen el lugar y el tiempo en que transcurre, éstos pueden omitirse. Los elementos del relato según cada tratadista pueden apreciarse en su conjunto en el siguiente cuadro:

\begin{tabular}{|c|c|c|c|c|}
\hline \multicolumn{2}{|c|}{ Teón 78-79 } & Hermógenes 4 & Aftonio 2-3 & Nicolás 13 \\
\hline Personaje & 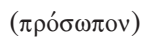 & & Personaje & Personaje \\
\hline hecho & $(\pi \rho \hat{\alpha} \gamma \mu \alpha)$ & Hecho & hecho & hecho \\
\hline tiempo & 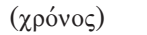 & & tiempo & tiempo \\
\hline lugar & ( & & lugar & lugar \\
\hline modo & ( & & modo & modo \\
\hline causa & $(\alpha i \tau i \alpha)$ & & causa & causa \\
\hline & & & & instrumento (ín $\lambda \eta)$ \\
\hline
\end{tabular}

En todas las partes del discurso ${ }^{16}$ puede encontrarse un relato no acabado, es decir, sin la totalidad de los elementos.

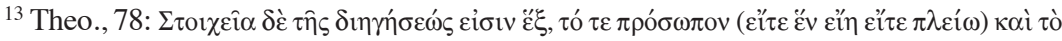

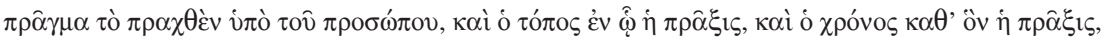

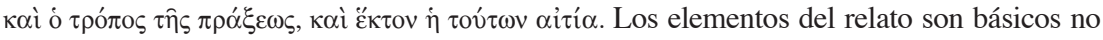
sólo para la elaboración de este ejercicio, sino también para la argumentación, cf. Theo., 94 y Aphth., 22. En Cic., Inv., 1, 34-41 se detallan los atributos del personaje y del hecho de manera muy precisa dentro de la exposición de la argumentación, pues en ese tratado la narración se centra especialmente en los hechos y en las personas.

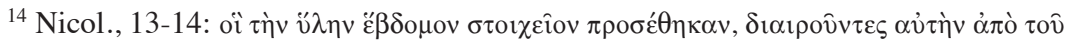

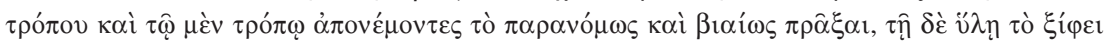

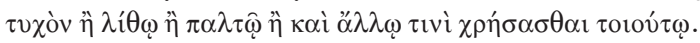

15 Theo., 78.

${ }^{16}$ Cf. Rabe, 1928, p. 106.
} 


\begin{tabular}{|c|c|c|}
\hline 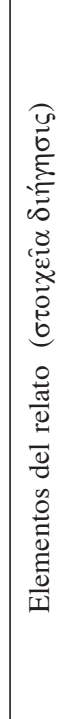 & $\begin{array}{l}\text { Personaje } \\
\left(\pi \rho \sigma_{\sigma} \omega \pi \mathrm{ov}\right) \\
\text { hecho } \\
(\pi \rho \hat{\alpha} \gamma \mu \alpha) \\
\text { tiempo } \\
(\chi \rho o ́ v o \varsigma)\end{array}$ & $\begin{array}{l}\text { Linaje, naturaleza, educación, disposición, edad, fortuna, intención, } \\
\text { acción, discursos, muerte, circunstancias posteriores a la muerte. } \\
\text { Grande / pequeño; peligroso / sin peligro; posible / imposible; fácil / } \\
\text { difícil; necesario / innecesario; útil / inútil; justo / injusto; glorioso / } \\
\text { sin gloria. } \\
\text { Pasado, presente, futuro; circunstancias anteriores / posteriores; si de } \\
\text { época presente / antigua; días de asuntos comunes / privados; invierno, } \\
\text { primavera, verano u otoño; de noche / de día; en asamblea, procesión o } \\
\text { fiesta; si durante bodas, banquete, duelo u otra circunstancia. } \\
\text { Extensión, distancia; ciudad / región vecina; sagrado / público, propio } \\
\text { / ajeno, desierto / habitado, fortificado / inseguro, llano / montañoso, } \\
\text { seco / húmedo, sin / con árboles. } \\
\text { Involuntariamente: por ignorancia, azar o necesidad. } \\
\text { Voluntariamente: con violencia, furtivamente o con engaño. } \\
\text { Si por adquirir bienes, huir de desgracias, amistad, por una mujer, } \\
\text { por los hijos, por pasiones (cólera, amor, odio, envidia, compasión, } \\
\text { embriaguez, etc.). }\end{array}$ \\
\hline
\end{tabular}

Como puede apreciarse, al personaje acompañan el linaje, la naturaleza, la educación, la disposición, la edad, la fortuna, la intención, la acción, los discursos, la muerte y las circunstancias posteriores a la muerte. ${ }^{17} \mathrm{La}$ totalidad de estos elementos nos hace pensar de inmediato en su semejanza con los topoi a partir de los que se desarrolla un encomio. ${ }^{18}$

El hecho es, como ya ha quedado dicho, la parte más importante del relato, su razón de ser, y a partir de él se construye la narración en su totalidad, hasta el punto de ser el elemento central para Hermógenes, que no se ocupa de hacer mención precisa de los demás elementos de la narración, sino más bien de lo pertinente a sus géneros y modalidades. ${ }^{19}$

Al tiempo acompañan: "el pasado, el presente, el futuro, qué ha ocurrido antes o después, etc [...]". ${ }^{20}$ Este elemento es muy importante en la narración, ya que es lo que proporciona al relato coherencia

${ }^{17}$ Theo., 78. Butts, 1990, pp. 363-366, hace un paralelo entre los atributos del personaje enumerados por Teón y los enumerados por Cic., Inv., I, 24, 34.

${ }^{18}$ Sobre el encomio, cf. Theo., 109-112; Hermog., Prog., 14-18; Aphth., 21-31; Nicol., 47-58; Lib., Prog., 209-328 y Quint., 3, 7.

${ }^{19}$ Hermog., Prog. 4-6.

${ }^{20}$ Theo., 78-79. 
y claridad. No obstante, muy a menudo queda expresado solamente por el tiempo verbal, razón por la que no es un elemento de aparición imprescindible, o al menos, de aparición explícita en las narraciones.

$\mathrm{Si}$ atendemos a las características propias del lugar, ${ }^{21}$ apreciaremos que son ideales para el detalle del relato y, por ello, contribuyen en gran manera al desarrollo de la descripción.

Las referencias de los manuales sobre el modo se reducen a si se obró de manera involuntaria o voluntaria, y cada una de éstas se subdivide en tres: lo involuntario, en si se obró por ignorancia, azar o necesidad, y lo voluntario, en si con violencia, furtivamente o por medio de un engaño. ${ }^{22}$ Es más común en los relatos la omisión de lugar y tiempo que la de modo. Por lo general, este último suele aparecer, ya que proporciona un matiz determinado a la narración.

A la causa de las acciones acompañan el porqué (por amistad o pasión), por quién (por una mujer o por los hijos), o con qué fin se han hecho. ${ }^{23} \mathrm{La}$ importancia de la causa estriba en que también proporciona atributos del personaje, puesto que el móvil o los móviles de una acción precisan rasgos de su carácter, que pueden contribuir al desarrollo de una etopeya, en el caso de que el autor así lo prevea. Las alocuciones aportan mucho a la caracterización, pues a través de sus propias palabras el personaje revelará sus cualidades (autocaracterización).

\section{Cualidades del relato}

A continuación, Teón expone las virtudes del relato, que varían en cada autor. Para este rétor son tres: claridad,$^{24}$ concisión y verosimilitud,${ }^{25}$ a las

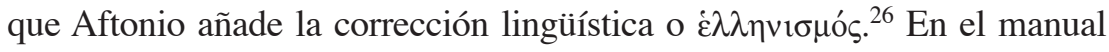
de Nicolás, en cambio, las cualidades enumeradas son cinco, pero en rea-

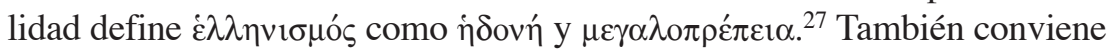

\footnotetext{
21 Theo., 79.

${ }^{22} \mathrm{Ib}$.

${ }^{23} \mathrm{Ib}$.

${ }^{24}$ Sobre la virtud de la claridad, cf. Arist., Rh., 1404b.

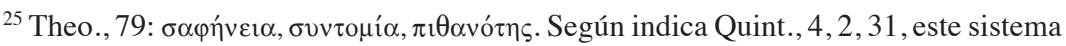
de virtudes deriva de Isócrates.

${ }^{26}$ Aphth., 3.

${ }^{27}$ Nicol., 14.
} 
considerar para estos aspectos la Retórica a Alejandro, donde se exponen las razones por las cuales el relato debe tener semejantes cualidades:

Tenemos que hacerlo con claridad, brevedad y credibilidad; con claridad ( $\sigma \alpha \varphi \hat{\omega} \varsigma)$, para que comprendan lo que se dice,28 concisamente ( $\sigma v v \tau$ tó $\mu \varsigma$ ), para que lo recuerden; con credibilidad $(\pi 1 \sigma \tau \hat{\omega} \varsigma)$, para que no rechacen nuestras explicaciones antes de que las confirmemos mediante argumentos y justificaciones. ${ }^{29}$

Teón señala que es necesario que la narración tenga todas las virtudes en el más alto grado, pero si esto fuera imposible, aconseja que la concisión no sea contraria a la claridad y a la verosimilitud, ya que si ésta falta, cuanto más clara y concisa sea la narración, resultará menos creíble. ${ }^{30}$ La narración concisa, según Teón, se logra ciñéndose al tema central del conjunto de la materia propuesta. ${ }^{31}$ Sin embargo, en relación con la brevedad, prescribe que lo que vaya a afligir a los oyentes se narre lo más rápidamente posible,$^{32}$ como hace Homero en la Ilíada al decir simplemente: "yace Patroclo", mientras que en lo que cause alegría, aconseja demorarse, como cuando Odiseo cuenta a los feacios sus propias vivencias.

\begin{tabular}{|c|c|c|c|c|c|}
\hline \multirow[b]{2}{*}{ 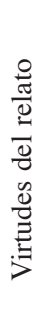 } & \multicolumn{2}{|c|}{ Teón 79-81 } & Aftonio 3 & Nicol & ás 12-14 \\
\hline & $\begin{array}{l}\text { Claridad } \\
\text { concisión } \\
\text { verosimilitud }\end{array}$ & 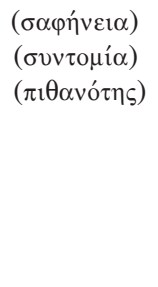 & $\begin{array}{l}\text { Claridad } \\
\text { concisión } \\
\text { verosimilitud } \\
\text { corrección } \\
\text { lingüística } \\
(\dot{\varepsilon} \lambda \lambda \eta v \imath \mu \mu o ́ \varsigma)\end{array}$ & $\begin{array}{l}\text { Claridad } \\
\text { concisión } \\
\text { verosimilitud } \\
\text { atractivo } \\
\text { grandeza }\end{array}$ & $\begin{array}{l}\left(\dot{\eta} \delta \circ v^{\prime}\right) \\
(\mu \varepsilon \gamma \alpha \lambda \circ \pi \rho \varepsilon ́ \pi \varepsilon 1 \alpha)\end{array}$ \\
\hline
\end{tabular}

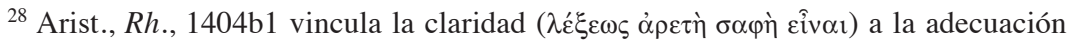
$(\pi \rho \varepsilon ́ \pi \circ v \sigma \alpha)$, lo que estaría muy relacionado con la verosimilitud, tal como es planteado en Theo., 84.

${ }^{29}$ Rh. ad Alex., 1438a5.

30 Theo., 79.

${ }^{31}$ Theo., 83. Men. Rh., 389 no opina lo mismo, pues para él presentar los hechos desnudos carece de encanto.

32 Theo., 80 . 
Únicamente Hermógenes no hace mención de las virtudes propias del relato, como puede apreciarse a continuación:

Aristóteles en su Retórica no coincide en que la narración deba ser breve, sino en la justa medida, pues debe expresar lo que aclare el asunto o lo que permita suponer qué ha ocurrido realmente. ${ }^{33}$ Nicolás también aboga por la extensión en aras de la claridad: lo óptimo es que vayan brevedad y claridad juntas, pero aquélla debe subordinarse a ésta. ${ }^{34}$ Buen ejemplo de la aplicación de este ideal son los relatos de Libanio de Antioquía, de extensión variable por primar en ellos la claridad..$^{35}$

La verosimilitud ( $\pi \theta \alpha$ vó $\left.\tau_{\varsigma}\right)$ es la cualidad más importante del relato y está muy relacionada con la probabilidad, ${ }^{36}$ por la que se da cabida a cierta cantidad de detalles para hacer el asunto creíble a través de la referencia a determinados aspectos de la narración. La Retórica a Herenio, por su parte, propone que, para lograr la verosimilitud, se respeten: la opinión común, la naturaleza, la duración de los hechos, la dignidad de los personajes, los motivos de las decisiones y la adecuación de los lugares. ${ }^{37}$ En ello viene a redundar lo expuesto por Teón sobre la verosimilitud, en pro de la que se deben adoptar modos de expresión apropiados a los personajes, a los hechos, a los lugares y a las circunstancias. ${ }^{38}$

Dentro del estilo de la exposición de los hechos para lograr la $\sigma \alpha \varphi \eta ́ v \varepsilon 1 \alpha$, Teón aconseja "evitar introducir en medio de una narración digresiones extensas", pero sí recomienda alguna breve, "ya que hace que descanse la atención de los oyentes". ${ }^{39}$ El mismo recurso sugiere Menandro, el rétor, a mitad de una descripción, para tener "ocasión de relajar el estilo [...] y de

\footnotetext{
${ }^{33}$ Arist., Rh., $1416 \mathrm{~b} 35$.

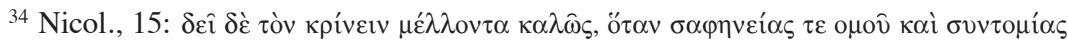

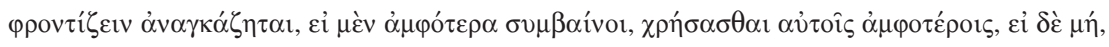

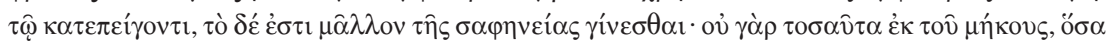

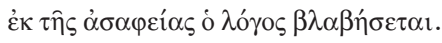

${ }^{35}$ Lib., Prog., 29-58.

${ }^{36}$ Cf. Quint., 4, 2, 31 y Rapp, 1998,pp. 442-443. Verosimilitud y probabilidad ayudan a dar por verdadero un hecho y, por ello, una narración puede servir de exemplum. La probabilidad surte efecto por basarse en la expresión de sentimientos o pensamientos que casi todos compartimos.

${ }^{37}$ Auct. ad Her., I, 9, 16.

38 Theo., 84 .

39 Theo., 80 .
} 
dar voz a una región o a un río", es decir, hacer una prosopopeya, antes de continuar con la descripción. ${ }^{40}$

\section{Modos de exposición}

Después de desaconsejar el uso de términos poéticos, inventados, figurados, antiguos, extranjeros, homónimos y ambiguos, que serían un obstáculo para la credibilidad de la narración, ${ }^{41}$ Teón enumera en el apartado del relato, como ya ha hecho en el ejercicio de la fábula y con mayor amplitud en el de la chreia ${ }^{42}$ los diversos aspectos en la presentación de los

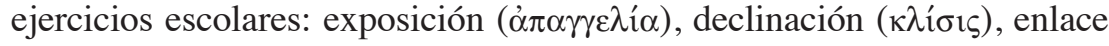

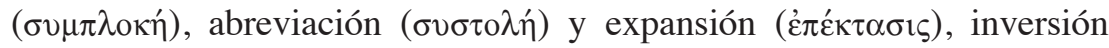

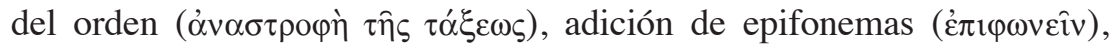

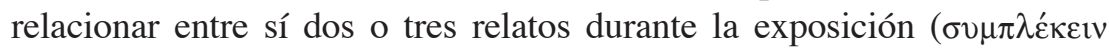

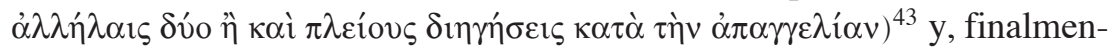

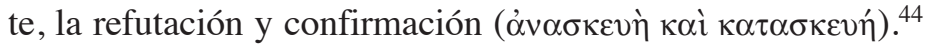

La exposición ( $\dot{\alpha} \pi \alpha \gamma \gamma \varepsilon \lambda i \alpha)$ de un relato debe reunir, como ya se ha dicho, las cualidades de claridad, concisión y verosimilitud. El apartado de "exposición" concierne a todos los ejercicios; para lograr la claridad y la evidencia en la expresión contribuye también el ejercicio de la elaboración ${ }^{45}$ "qui ajoute ce qui manque dans la pensée et dans l'expression". ${ }^{46}$

La declinación ( $\kappa \lambda i ́ \sigma \mathrm{r} \varsigma$ ) implica números y casos, ${ }^{47}$ entre los cuales hay que poner especial interés en el acusativo, pues, según Teón, en él están expuestas la mayor parte de las fábulas, además de resultar grata la variación del caso. Demetrio también propone comenzar los pasajes narrativos con el nominativo o el acusativo, ya que los demás casos

\footnotetext{
${ }^{40}$ Men., Rh., 374. Las digresiones deben ser muy breves, según Quint., 4, 3, 8: verum haec breviter omnia.

${ }^{41}$ Theo., 81-82. También Quint., 4, 1, 54 propone el uso del lenguaje sencillo con el mismo objeto: facie simplicis sumptique ex proximo sermonis fidem quoque adquirit.

${ }^{42}$ Fábula: Theo 74-76; chreia (sólo en este ejercicio añade la réplica): Theo 101-105.

43 Theo., 91.

44 Theo., 85-86.

45 Theo., 71.

${ }^{46}$ Patillon-Bolognesi, 1997, p. 110.

${ }^{47}$ Para referencias de textos declinados conservados en papiros, óstraca o tablillas, cf. Cribiore, 1996, pp. 225-269. Como ejemplos de ejercicios de declinación, cf. HockO’Neil, 2002, pp. 51-77.
} 
provocan cierta oscuridad. ${ }^{48} \mathrm{El}$ uso de la klisis se debe a la lengua misma, ya que no podemos narrar en un caso que no sea apropiado a las normas gramaticales y sintácticas. Por supuesto, no encontraremos ningún relato declinado en ningún autor con pretensiones literarias, por la necesaria distancia que éstos toman respecto a los ejercicios de escuela, pero sí encontraremos rasgos de ella. Recordemos que el autor del De Sublimitate dice que el polýptoton y la metabolé "son de gran efecto y colaboran al ornato, a toda clase de estilo y a la pasión". ${ }^{49}$ De ello se deduce que el objetivo de tal ejercicio era enseñar a hacer uso de la declinación de las frases para variar el estilo y para integrar ágilmente relatos preexistentes en el nuevo contexto.

Al apartado sobre el ejercicio de la fábula nos remite Teón a la teoría

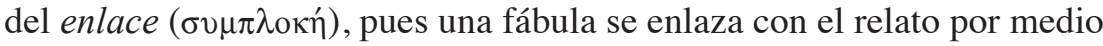
de una comparación:

Tras exponer la fábula ofrecemos el relato [...] como el ejemplo ficticio de que "un camello, que había deseado vivamente tener cuernos, se vio privado también de las orejas". Tras decir esto primero, ofreceremos el relato del modo siguiente: "A mí me parece que algo parecido a ( $\pi \alpha \rho \alpha \pi \lambda \eta ́ \sigma$ ióv $\tau i ́)$ lo del camello ese le ocurrió también al lidio Creso". 50

La abreviación ( $\sigma \nu \sigma \tau \lambda \eta \dot{)}$ se consigue refiriendo el relato sin prolongar las prosopopeyas y sin incluir descripciones. ${ }^{51}$

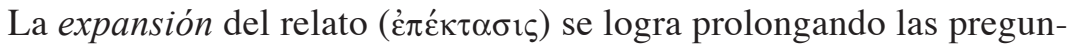
tas y respuestas, o las acciones y experiencias que contenga, ${ }^{52}$ así como mediante prosopopeyas y descripciones, según aconseja en el apartado de la fábula. ${ }^{53}$ Las prácticas de expansión y abreviación expuestas en dicho ejercicio, en el relato y en la chreia están clasificadas también como formas de paráfrasis. ${ }^{54}$ Teón trata la expansión como una forma de ejercitación en el relato; sin embargo, en otro lugar de su tratado acon-

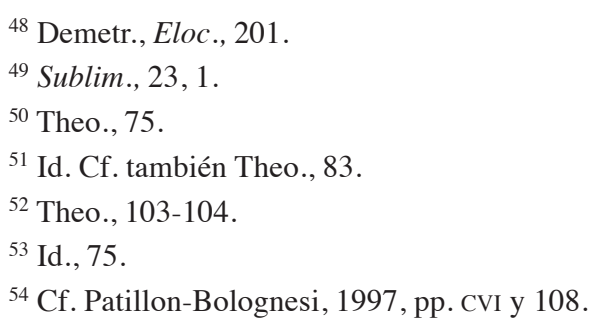


seja evitar el uso de frases que puedan resumirse en una palabra, así como el de los sinónimos, los cuales alargan el relato sin necesidad. ${ }^{55}$

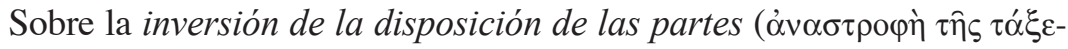
$\omega \varsigma$ ), es decir, sobre seguir o no el orden lógico del relato, ${ }^{56}$ Teón nos indica que el orden de la narración puede ser muy variado, como bien ejemplifica con la Odisea o con el relato de Cambises en Heródoto. ${ }^{57}$ En cambio, el autor de la Retórica a Alejandro no es partidario de alterar el orden, ya que considera que narrar los hechos de manera sucesiva contribuye a la claridad. ${ }^{58} \mathrm{El}$ orden de los elementos a la hora de narrar corresponde a causas como la variación para evitar la monotonía, por razones de estilo o por los intereses del autor, juicio que corrobora Quintiliano, quien opina que debe adoptarse el orden más conveniente, ${ }^{59}$ con la convención de que si no se sigue el orden lógico, algo frecuente en muchos relatos, se evite la confusión mediante la repetición de alguno de los elementos. ${ }^{60}$ Otra perspectiva es la de Cicerón en su De inventione, donde nos indica que se consigue una mayor brevedad comenzando la narración de los hechos en el punto preciso, de forma que a partir de unos puedan sobreentenderse otros. ${ }^{61}$

Una narración puede ser concluida añadiendo un epifonema, recurso que sólo aparece en los Ejercicios preparatorios de Teón; su uso es más apropiado para el teatro y la escena, aunque lo podemos encontrar con cierta frecuencia en obras de todos los géneros. Según este rétor, "añadir

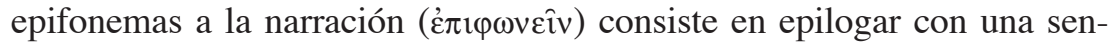
tencia cada una de las partes de la misma", ${ }^{62}$ consejo que también encontramos en la Retórica a Alejandro para concluir cada una de las partes del encomio ${ }^{63}$ práctica que desaprueba rotundamente Quintiliano. ${ }^{64}$

${ }^{55}$ Theo., 84. Sobre la abreviación del discurso, cf. también Rh. ad Alex., 1434 b5.

56 Theo., 86.

${ }^{57}$ Id., 86-87.

${ }^{58}$ Rh. ad Alex., 1438a.

${ }^{59}$ Quint., 4, 2, 83.

${ }^{60}$ Hermog., Id., I, 239.

${ }^{61}$ Cic., Inv., I, 20, 28.

${ }^{62}$ Theo., 91. Cf. Patillon-Bolognesi, 1997, pp. LXIV-LXIX. Según Kriel, 1961, p. 86 la

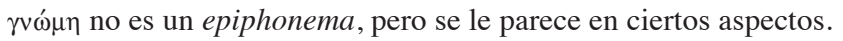

${ }^{63}$ Rh. ad Alex., 1441a12, 1441b15, $1441 \mathrm{~b} 16$.

${ }^{64}$ Quintiliano piensa que es pueril la enseñanza escolar de que el paso de un apartado a otro se realice con una sentencia y sea bien acogido como si de un recurso mágico 
Otra definición de epifonema la hallamos en el De elocutione de Deme-

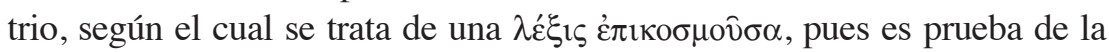
riqueza del lenguaje ${ }^{65}$ además, según Teón, el uso frecuente y discreto de los dichos gnómicos confieren a la narración cierta gracia. Entendido también como frase que corrobora lo dicho, Quintiliano lo define como summa acclamatio que sigue a la narración o a la demostración. ${ }^{66}$ El epifonema, según este autor, es, además, una de las cuatro posibles funciones de la sententia $;{ }^{67}$ es una especie de comentario sentencioso que, como ya se ha dicho, puede no ser precisamente una máxima, aunque ambos comparten el sentido estético y el carácter conclusivo, como podemos apreciar en este ejemplo tomado de la Homilia in divites, de Basilio de Cesarea:

¿Qué vecino, qué doméstico, quién que negocie con ellos no será robado? Nada resiste el poder de la riqueza, todo se somete a la tiranía, todo tiembla ante su dominio, porque todo el que ha sido injuriado tiene más cuenta de no padecer otro mal que de tomar venganza de lo que le ha ocurrido antes. ${ }^{6}{ }^{6}$

El epifonema inicial anuncia el tema del relato de manera global; por el contrario, el final es concluyente. Ambas posiciones se encuentran en las fábulas, como claramente refiere Aftonio: "A la moraleja, en función de la cual se dispone la fábula, la llamarás promitio si la colocas delante; epimitio, en cambio, si la pones al final". ${ }^{69}$

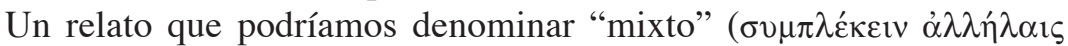

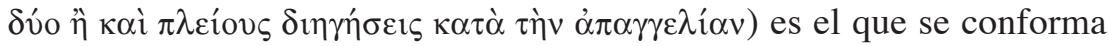

se tratase: Illa uero frigida et puerilis est in scholis adfectatio, ut ipse transitus efficiat aliquam utique sententiam et huius uelut praestigiae plausum petat $(4,1,77)$, y en otro lugar $(8,5,14)$ : neque enim possunt tam multae bonae sententiae esse, quam necesse est multae sint clausulae.

${ }^{65}$ Demetr., Eloc., 2, 106-108.

${ }^{66}$ Quint., 8, 5, 11. Una definición más completa de epifonema la encontramos en Fontanier, 1977, p. 386: 'L'Épiphonème est une réflexion vive et courte, ou un trait d'esprit, d'imagination, ou de sentiment, à l'ocassion d'un récit ou d'un détail quelconque, mais qui s'en détache absolument par sa généralité ou par son objet particulier, et le précède, l'accompagne, ou le suit, en se plaçant avant ou après une phrase, ou entre deux phrases; en sorte qu'il est, suivant sa position, iniciatif, terminatif ou interjectif'.

${ }^{67}$ Quint., 8, 5, 9-13: como entimema, como epifonema, como noema y como cláusula. Para Malosse, 2000, pp. 195-196 el epifonema es una manera de amplificación.

${ }^{68}$ Bas., Div., 57, 27-59, 1.

${ }^{69}$ Aphth., 1-2. 
de la relación de dos o más relatos de distinto modo, Teón propone "exponer una parte del relato según el modo enunciativo, otra según el de asíndeton y la restante variando la expresión como uno quiera" de lo que nos da un ejemplo tomado del Panegírico IV de Isócrates: ${ }^{70}$

'Llegaron los hijos de Hércules y poco antes que estos Adrasto, el hijo de Tálao y rey de Argos; éste, después de haber fracasado en la expedición contra Tebas' [...]. Y de nuevo: 'Pues, cuando Grecia era todavía pobre, llegaron a nuestro país los tracios con Eumolpo, el hijo de Poseidón, los escitas con las Amazonas, las hijas de Ares, no por el mismo tiempo' $\left[\ldots . . .^{71}\right.$

El último posible tratamiento de los ejercicios que propone Teón es el referente a la argumentación propiamente dicha; la refutación se elabora a partir de determinados lugares de argumentación para objetar la narración, y de sus contrarios en el caso de la confirmación. Al decir de Aftonio: "Una refutación es la invalidación del tema propuesto; una confirmación, por el contrario, su consolidación. No se han de refutar ni confirmar los temas que son enteramente falsos, como, por ejemplo, las fábulas, sino que es, sin duda, necesario que las refutaciones y confirmaciones se hagan sobre aquellos temas que admiten la argumentación en uno y otro sentido". ${ }^{72}$

Teón indica que para refutar un relato son adecuados los lugares de argumentación basados en la falsedad y la imposibilidad "como hace Tucídides al refutar el que Hiparco fuese muerto por los partidarios de Harmodio y Aristogitón cuando era tirano, y Heródoto al oponerse a quienes opinaban que Cambises era egipcio por línea materna". ${ }^{73}$ Los argumentos han de tomarse de los siguientes topoi argumentativos: "de la oscuridad, de la inverosimilitud, de la inadecuación, de la imperfección, de la redundancia, de la novedad, de la contradicción, de la disposición de las partes, de la inconveniencia, de la desigualdad y de la falsedad".

A continuación Teón ejemplifica:

La oscuridad se produce o por medio de un término, o incluso de más: por medio de uno, cuando alguien se sirve de palabras desacostumbradas

\footnotetext{
${ }^{70}$ Isoc., Pan., 4, 54-55 y 68.

71 Theo., 92-93.

72 Aphth., 11.

${ }^{73}$ Theo., 76-77.
} 
u homónimas; por medio de más, cuando es posible entender lo dicho de muchas maneras, sin que nada se añada ni se suprima, por ejemplo: '̇ं $\gamma$ ́ $\sigma^{\prime}$

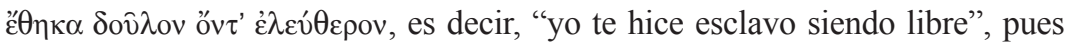
no está claro si lo hizo libre en lugar de esclavo, o esclavo en lugar de libre...

Lo inverosímil es lo que puede haber sucedido o haber sido dicho, pero se duda que haya sucedido o se haya dicho, bien por el personaje al que se atribuye la acción o el discurso, o por el lugar en el que se dice que algo ha sucedido o se ha dicho, o por el tiempo durante el cual se dice que algo ha sucedido o se ha dicho, o por el modo de la acción o del discurso, o por la causa de esas mismas actuaciones, si decimos nosotros que no es verosímil que tal individuo haya hecho eso o haya dicho esto otro en ese lugar, o durante ese tiempo, o de ese modo, o por esa causa; y lo mismo hay que decir también sobre la inadecuación.

La imperfección es equivalente a la redundancia, cuando se omite algo de lo que puede ser dicho, o se dice algo que no tiene importancia, ya sea un personaje, un hecho, un tiempo, un modo, un lugar, una causa o algo semejante.

La novedad es lo que está al margen de la historia tenida como cierta, o lo que se dice al margen de las opiniones comunes, como si alguien dijera que los hombres no han sido modelados por Prometeo, sino por algún otro de los dioses, o si dijera que el asno es sagaz o la zorra necia.

El lugar basado en la contradicción es tal cuando demostramos que el propio escritor se contradice a sí mismo; y debemos servirnos de él no al comienzo, sino cuando refutemos algo de la parte central o final, y a continuación hemos de demostrar que eso se opone a lo dicho antes.

A partir de la disposición, sin embargo, argumentaremos demostrando que lo que era necesario que se hubiese dicho al comienzo no se ha expuesto al principio, y que lo que era preciso que se dijese al final ha sido expuesto previamente en otro lugar y, en conjunto, en la medida en que podamos, que cada cosa se ha dicho sin seguir la disposición conveniente. ${ }^{74}$

La confirmación se hará a partir de los lugares de argumentación contrarios.

Sin duda, sólo en los ejercicios escolares era posible argumentar los relatos a partir de todos los topoi, pues no hallaremos tal desarrollo en las obras literarias. Los siguientes ejemplos proporcionados por Aftonio ilustran bien cuál era la labor que debía llevarse a cabo en clase argumentando primero, a modo de confirmación, que es probable la historia de Dafne, y después, como refutación, que no es posible:

\footnotetext{
${ }^{74} \mathrm{Ib}$.
} 
Quien habla en contra de los poetas yo creo que se opone a las propias Musas. Si todo cuanto cantan los poetas lo exponen por la voluntad de ellas, ¿cómo no se opondría a las Musas quien pretendiese censurar la obra de los poetas? Sin duda, yo admito la opinión de todos ellos, pero, entre todos, principalmente la del que emitió la reflexión de que Dafne era la amada del Pitio. Algunos desconfían de él cuando dice tales cosas.

Dafne, afirma, nació de la Tierra y de Ladón. ¡Por los dioses!, ¿por qué esto es increíble?, ¿no son el agua y la tierra el origen común de todas las cosas?, ¿no preceden los elementos a la simiente de la vida? Si todo lo que nace surge de la tierra y del agua, Dafne confirma el origen común de todas las cosas por haber nacido de la Tierra y de Ladón. Habiendo nacido de donde todo se origina aventajaba en belleza a las demás, y muy razonablemente, pues las primicias de la tierra surgen con la belleza propia de la naturaleza. En efecto, hay fijadas muchas transformaciones de cuerpos en los cuales se contempla la belleza, pero el cuerpo que aparece el primero es el más hermoso de todos. Por tanto, Dafne lógicamente ofreció el arquetipo por nacer de la tierra antes que las demás.

Como Dafne se distinguía por su belleza, el Pitio se enamoró de la joven, y muy razonablemente; pues toda la belleza que en la tierra existe procede de los dioses. Si la belleza es un bien más afortunado que los demás bienes que hay sobre la tierra (porque la belleza es un don de los dioses), tenía la belleza como enamorado a un dios, pues todos aman los dones que otorgan los dioses.

Aunque el dios estaba enamorado, prefería curar su sentimiento, pues las virtudes son de tales características que se poseen por la fuerza, y sin esfuerzo no es posible alcanzar una virtud. Por lo cual sufría al desearla $\mathrm{y}$, aunque sufría, no logró conquistarla, pues no es posible contemplar el término de la virtud. Por eso dicen que el Pitio estaba enamorado, y no acusan de ello a la tierra ni a la naturaleza de los dioses, sino que muestran como responsable a la naturaleza de la virtud. Así pues, caracteriza al perseguidor el objeto que persigue.

La madre acogía en su interior a la joven mientras huía pues todas las criaturas mortales son por naturaleza de la siguiente condición: se apresuran hacia el medio del que proceden. Por lo cual Dafne corre hacia la Tierra, puesto que de la Tierra procedía.

Y tras acoger a la muchacha la Tierra hizo brotar un árbol, pues ambas acciones están fijadas como propias de la tierra, tanto que caigan hombres en ella, como que de ella nazcan árboles.

Y el árbol, una vez aparecido, ha resultado motivo de honra para Apolo. Pues los dioses no dejan fuera de su providencia ni siquiera a los árboles, sino que también se coronan con ellos una vez que nacen, ya que las primicias 
de la tierra son consagradas a los dioses. $\mathrm{Y}$ ha resultado símbolo del arte adivinatoria, siendo apropiado, a mi entender, también esto, pues a la muchacha la llaman Casta y el profetizar procede de la castidad. Por consiguiente, como la muchacha no conoció el placer, se consagra a las virtudes, pues no sería posible que adivinara el futuro si hubiese padecido de incontinencia.

Por estas razones admiro a los poetas y por ello honro la poesía. ${ }^{75}$

Ahora veremos cómo hace Aftonio la refutación del mismo relato bajo el tópico de la imposibilidad:

Es absurdo oponerse a los poetas, pero ellos mismos provocan que se les replique al inventar previamente tal tipo de historias contra los dioses. ¿Cómo, pues, no es absurdo que ellos no hayan tenido ninguna consideración de los dioses y que nosotros, en cambio, tengamos consideración de los poetas? Así pues, yo me afligía por todos los dioses ultrajados, pero sobre todo por Apolo, a quien ellos han hecho protector de su propia arte, pues han inventado tales historias de Dafne con Apolo.

Dafne, afirman, nació de la Tierra y de Ladón, como aventajaba a la mayoría en belleza, se atraía como amante al Pitio. Éste la perseguía enamorado, pero en su persecución no lograba apresarla, sino que la Tierra tras acoger a su hija, hizo brotar el árbol que lleva el mismo nombre que la muchacha. Entonces, una vez metamorfoseada, el dios se coronó con ella, y el árbol se convirtió en corona ofrecida al trípode pitio a causa de su amor por la joven mortal, y las hojas se convirtieron en distintivo de su arte. Así pues, ésas son las historias que han inventado, pero es posible lograr su refutación a partir de los argumentos que siguen.

Dafne nació de Ladón y de la Tierra: ¿Qué garante ofrece de su linaje? Ella, en efecto, era un ser humano: mientras que ellos poseyeron una naturaleza diferente a ésta. ¿Cómo se une Ladón con la Tierra? ¿Inundándola con sus aguas?: sin duda, todos los ríos son denominados esposos de la Tierra, pues todos la inundan. Si un ser humano ha nacido de un río, es hora también de que nazca un río de los seres humanos, pues las sucesivas generaciones ponen en evidencia a los progenitores. ¿A qué llama unión de un río y de la tierra? El matrimonio es propio de los seres animados, mientras que la tierra no pertenece por naturaleza al género animado. Por consiguiente, o bien hemos de contar a Dafne entre las corrientes de agua, o bien hemos de considerar a Ladón como hombre.

Sin embargo, sea, admitamos con los poetas que Dafne nació de la Tierra y de Ladón. La niña, después de nacer, ¿junto a quiénes se crió?, ya que, aunque

\footnotetext{
${ }^{75}$ Aphth., 14-16.
} 
yo admita el nacimiento, su crianza resultaría imposible, pues ¿en dónde tenía la niña su morada? - "Junto a su padre, ipor Zeus!”. Y ¿qué ser humano soporta la vida en un río?: el padre habría ignorado si la ahogaba en las aguas o la criaba en las corrientes. - "Entonces la niña vivía bajo tierra junto a la madre". Sin duda, estaba oculta y al estar oculta no tenía observador. Era, pues, imposible que naciera la pasión por aquella cuya belleza se hallaba escondida.

Convengamos, si quieres, también en eso con los poetas. ¿Cómo un dios estaba enamorado y con ese deseo quebrantaba su naturaleza? El amor es la más dura de las pasiones existentes, y es impío imputar a los dioses las pasiones más terribles pues, si los dioses experimentan todos los sufrimientos, ¿en qué se diferenciarán ya de los mortales?; si soportan lo más terrible, el amor, ¿en qué se distinguen de la mayoría, puesto que soportan lo más penoso? Sin embargo, ni su naturaleza conoce la pasión ni el Pitio se mostraba enamorado.

¿Cómo el Pitio al perseguir a la muchacha se convirtió en un segundo mortal? ¿Los hombres aventajan a las mujeres y las mujeres han conseguido más que los dioses? ¿Lo que era un ser inferior entre los mortales los superó incluso? ¿Por qué la madre acogía a la muchacha mientras huía? ¿La unión conyugal está entre los actos mezquinos? y ¿de qué modo llegó ella a ser madre? ¿Acaso se halla entre los bienes?, y ¿por qué privó a su hija de los bienes? Por consiguiente, o bien no ha sido madre, o, si lo fue, la hemos de considerar incompetente.

¿Por qué la tierra entraba en contradicción con sus propias acciones? ¿Afligía al Pitio mientras la salvaba y, a su vez, le divertía mientras la transformaba? No era preciso que le divirtiera si quería afligirlo. ¿Por qué el dios se coronaba con el árbol junto a los trípodes? La rama resulta símbolo del placer, mientras que la adivinación se revela como prueba de virtud. Así pues, ¿cómo el Pitio unió lo que por naturaleza no está unido? ¿Por qué, pues, el motivo es mortal, pero la pasión es inmortal?

Baste ya con los poetas, no sea que parezca que hablo contra ellos. ${ }^{76}$

Ya que el objetivo era que el alumno se ejercitara en la argumentación, Teón propone servirse de los lugares en el siguiente orden: a partir de la oscuridad, a partir de la imposibilidad, a partir de la inverosimilitud, a partir de la falsedad, a partir de la inadecuación, a partir del orden en que fueron narrados los hechos y a partir de la inconveniencia:

En primer lugar, argumentaremos la narración a partir de la oscuridad, según todos los procedimientos que citamos con relación a la claridad; en

\footnotetext{
${ }^{76}$ Id., 11-13.
} 
segundo lugar, basándonos en la imposibilidad, mostrando que es imposible que el hecho haya sucedido del modo en que afirma el escritor, bien porque ni siquiera haya podido suceder en su conjunto, o bien porque los hechos narrados no sean contemporáneos: por ejemplo, es posible refutar a quienes dicen que Hércules dio muerte a Busiris, pues, según Hesíodo, Busiris es anterior a Hércules en once generaciones [...]. A continuación, si aceptáramos el hecho como posible, hemos de decir que es inverosímil; si es verosímil, examinaremos si es falso; si pareciera verdadero, buscaremos entonces si le falta o le sobra algo; a continuación, diremos que el escritor se contradice a sí mismo a lo largo de la narración; además, censuraremos también la disposición de las partes principales, en el caso de que no se hubiera hecho el relato del modo adecuado; y, si todo ello estuviera dispuesto como corresponde, entonces hemos de señalar que es inadecuado e inconveniente, pues hay hechos que sería necesario que no se hubiesen realizado, pero que, una vez realizados, conviene que se silencien, como si alguien, tras decir que Ayante Locrio cometió contra Atenea la clase de impiedades que se cuentan, a continuación supusiera que, sin sufrir desgracia alguna ni en el mar ni en su patria, acabó su vida en una vejez dichosa. ${ }^{77}$

Otra forma más abundante aún de argumentación es la combinación de todos los lugares antes mencionados con los elementos del relato: personaje, hecho, lugar, tiempo, modo y causa. Teón nos propone como ejemplo el topos argumentativo de la inverosimilitud en el relato de Medea. Nos dice:

Si refutamos la narración a partir de la inverosimilitud, haremos el examen como sigue: demostrando que es inverosímil tanto el personaje como el hecho realizado y el lugar en el que transcurre la acción, así como también el tiempo, el modo y su causa; por ejemplo, en el caso de Medea refutaremos a partir del personaje diciendo que es inverosímil que una madre haga daño a sus hijos; a partir de la acción, que no es lógico que los degüelle; a partir del lugar, que no les hubiera dado muerte en Corinto, en donde vivía Jasón, el padre de los niños; a partir del tiempo, que es inverosímil que lo hiciese en esa circunstancia, en la que ella, una mujer extranjera desterrada, estaba en condiciones de inferioridad ante su marido, mientras que Jasón había aumentado su poder al casarse con Glauce, la hija de Creonte, rey del lugar; a partir del modo, que hubiera intentado pasar inadvertida y no se hubiera servido de un puñal, sino de un veneno, sobre todo siendo hechicera; a partir de la causa, que es inverosímil que hubiera

\footnotetext{
${ }^{77}$ Theo., 93-94.
} 
dado muerte a sus hijos por la cólera que sentía hacia su marido, pues el infortunio no fue exclusivo de Jasón, sino que también fue común para ella; y especialmente para ella, en la medida en que las mujeres son de algún modo más sensibles a los sufrimientos. De igual modo, también en el caso de los otros lugares de argumentación examinaremos cada uno de los elementos básicos consecutivamente, argumentando a partir de los que sea posible; y a partir de los lugares de argumentación contrarios haremos la confirmación. ${ }^{78}$

\section{Modos de exposición}

Hay también distintos modos de exponer los hechos, que varían en los distintos tratadistas. La clasificación más completa la proporciona Teón, y únicamente no es incluida por Aftonio.

El relato de forma enunciativa puede ser afirmativo, negativo, asindético (Hermógenes opina que este modo es propio para los epílogos

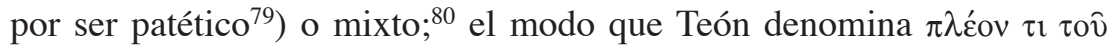

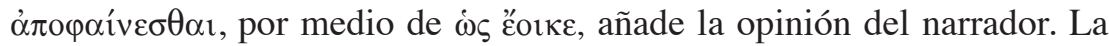
interrogación, ${ }^{81}$ indagación y duda no presentan diferencias en cuanto al aspecto formal, pues estos tres modos se formulan mediante una pregunta; sin embargo, Teón sí menciona las diferencias entre ellos, puesto que la interrogación supone obtener como respuesta un simple "sí" o un simple "no", 82 por lo que es apropiada para la argumentación; ${ }^{83}$ la indagación consistente en obtener información que ayude a contar el relato, y la duda, por su parte, supone una reflexión del narrador consigo mismo. Otros modos del relato son: orden, súplica, suposición y diálogo ${ }^{84}$

\footnotetext{
${ }^{78}$ Id., 94-95.

${ }^{79}$ Hermog., Prog., 6.

80 Theo., 90-91.

${ }^{81}$ La interrogación se entiende total, la indagación equivale a una interrogación parcial, cf. Theo., 97 y Reche, 1991, p. 94, n. 133.

${ }^{82}$ Patillon-Bolognesi, 1997, p. 51, n. 261, denomina a este modo "percontatif", pues no espera como respuesta simplemente un "sí" o un "no". En inglés son denominadas Yes / No-Questions.

${ }^{83}$ Cf. Hermog., Prog., 6; Nicol., 16.

${ }^{84}$ El relato en forma de diálogo preludia el ejercicio más avanzado de la etopeya. Algunos de estos modos (enunciación, interrogación e indagación) los refiere también Teón en el apartado de la elaboración de la chreia: 97-98.
} 
Nicolás añade en su manual el discurso indirecto, es decir, enunciativo oblicuo, y el de comparación, que recomienda usar siempre que la ocasión lo permita. ${ }^{85}$

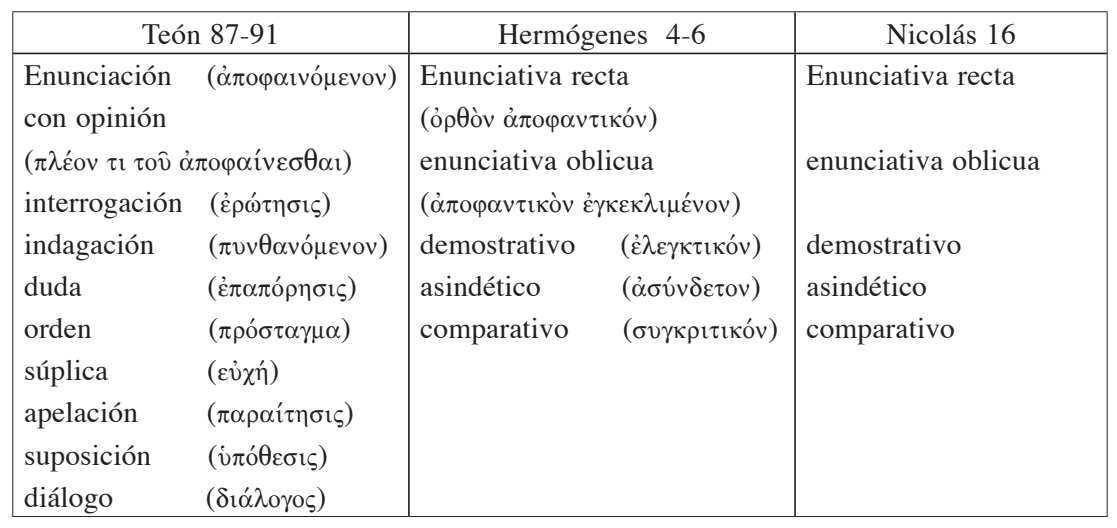

\section{Tipos de relato}

Dentro del apartado del relato, Teón no hace una clasificación de los géneros como los demás rétores, puesto que la ha hecho en la introducción al tratado, donde recomienda que el profesor recopile ejemplos apropiados para cada ejercicio. ${ }^{86} \mathrm{Su}$ clasificación es la más sencilla de todas. Para él los relatos son solamente de dos tipos: míticos ( $\mu v \theta \imath \alpha \alpha$ ) e históricos ( $\pi \rho \alpha \gamma \mu \alpha \tau \iota \kappa o ́)$, lo que se corresponde con su definición de relato: "Un relato es una composición expositiva de hechos que han sucedido o que se admiten como sucedidos". ${ }^{87}$

Para Hermógenes, en cambio, el relato puede ser mítico, ficticio o dramático, histórico y civil o privado. ${ }^{88}$ Ya que no todos los hechos narrados por un autor pueden ser verdaderos en el sentido de históricos, $\mathrm{o}$

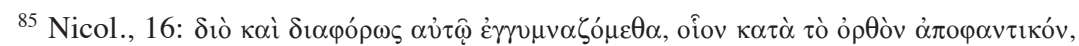

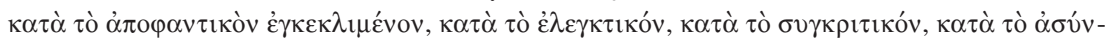
$\delta \varepsilon \tau$ ov.

${ }^{86}$ Theo., 66.

${ }^{87}$ Theo., 78.

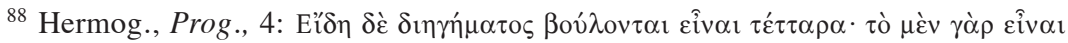

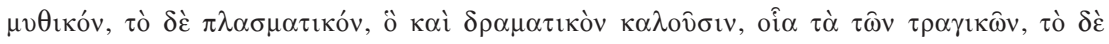

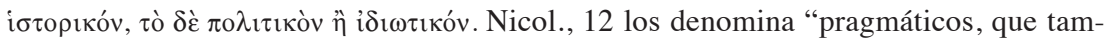
bién llaman judiciales o ficticios". 
verosímiles en cuanto probables, el de los relatos ficticios es un género necesario pues no puede anularse la fuerza de la tradición, como confirman los inmemoriales mitos. ${ }^{89} \mathrm{R}$. Meijering concluye al respecto que "in Hellenistic theory i $\sigma \tau$ opí $\alpha$ consists of legendary matter rather than of true facts of history; it is traditional and in any case potentially ( $\dot{\varepsilon} v$

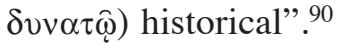

Nicolás, por su parte, nos proporciona dos clasificaciones. Los relatos pueden ser descriptivos, dramáticos y mixtos (i. e., mezcla de los dos anteriores); y además míticos, históricos, pragmáticos o judiciales y ficticios..$^{91}$

Para abarcar esta clasificación en su totalidad proporcionamos el siguiente cuadro:

\begin{tabular}{|c|c|c|c|}
\hline Teón 66 & Hermógenes 4 & Aftonio 2 & Nicolás 12 \\
\hline Mítico & Mítico $\left(\mu \nu \theta_{\imath \kappa o ́ v}\right)$ & & Míticos $\quad(\mu v \theta$ เкоí $)$ \\
\hline & & & 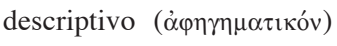 \\
\hline \multirow{7}{*}{ histórico } & ficticio o dramático & Dramáticos o & dramático $\quad(\delta \rho \alpha \mu \alpha \tau \iota \kappa o ́ v)$ \\
\hline & 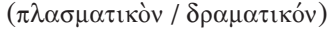 & ficticios & $(\pi \lambda \alpha \sigma \mu \alpha \tau \imath \kappa о i ́)$ \\
\hline & & & ( $\mu \iota \kappa \tau o ́ v)$ \\
\hline & 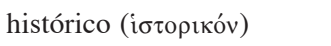 & históricos & 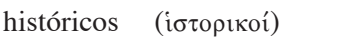 \\
\hline & & (ібторıкоí) & pragmáticos o judiciales \\
\hline & civil o privado & civiles & 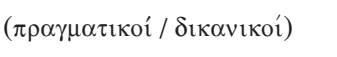 \\
\hline & ( & $(\pi \circ \lambda ı \tau 1 \kappa о i ́)$ & \\
\hline
\end{tabular}

Para el relato de tipo mítico Teón nos proporciona su argumentación:

Esos mismos lugares (se refiere a los elementos del relato) son apropiados también para las narraciones míticas, las contadas tanto por poetas como por historiadores sobre dioses y héroes e, incluso, sobre los que han sufrido cambios en su naturaleza, como las que algunos cuentan sobre Pegaso, Erictonio, Quimera, Hipocentauros y seres semejantes. Y el hecho de no sólo refutar tales narraciones míticas, sino también exponer de qué fuente ha

${ }^{89}$ En el escolio V, que nos proporciona la edición de Patillon-Bolognesi, 1997, p. 116, se toman en consideración dos criterios para reconocer un hecho ficticio como real: la aceptación por la mayoría como hechos reales y la autoridad de los filósofos y los poetas.

${ }^{90}$ Meijering, 1987, p. 78.

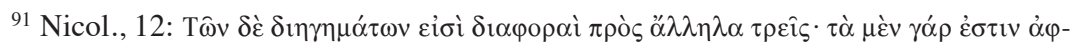

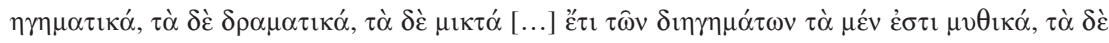

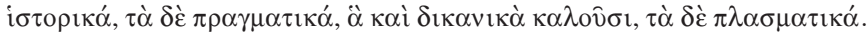


surgido tal relato es propio de un dominio superior al de la mayoría, como ha hecho Heródoto en el libro segundo al narrar cómo volaron las palomas desde Egipto y una logró llegar al santuario de Dodona y la otra al de Amón. Y al explicar tal relato mítico afirma que unas vírgenes sacerdotisas procedentes de la Tebas egipcia, de las cuales una fue vendida al santuario de Dodona la otra al de Amón, y como hablaban en lengua bárbara y de un modo ininteligible para los del lugar preví la creencia de que eran aves. Platón, en el Fedro, aceptando el relato sobre Oritía y Bóreas, afirma que un soplo del viento bóreas empujó desde lo alto de unas rocas cercanas a Oritía mientras jugaba con Farmacía y que por eso, sin duda, se dijo que había sido arrebatada por Bóreas. Por otro lado, también Éforo se sirve de esta modalidad en su libro cuarto: "Titio, en efecto, hombre inmoral y violento, era soberano de Panopeo; Pitón era de naturaleza salvaje, la llamada 'serpiente'; los que vivían en las cercanías de la en otro tiempo Flegras, denominada ahora 'Palene', eran hombres crueles, sacrílegos y antropófagos, los llamados 'Gigantes', a los que se dice que Hércules sometió tras apoderarse de Troya y, como Hércules y sus compañeros, que eran pocos, vencieron a los Gigantes, que eran muy numerosos e impíos para con los dioses, a todos les parecía que lo del combate había sido una hazaña", y cuantas otras aclaraciones semejantes hace con relación a Licurgo, a Minos y Radamantis, a Zeus y los Curetes, y a los otros mitos contados en Creta. ${ }^{92}$

\section{Conclusión}

El apendizaje de los progymnásmata era gradual, se comenzaba con los más sencillos (fábula y relato) y se concluía con los más complicados (tesis y propuesta de ley). En los distintos tipos de relato vemos el preludio de otros progymnásmata de mayor envergadura: el relato en modo comparativo prepara para la posterior composición de una sýnkrisis formal; el relato en forma dialogada, para la realización de una etopeya; el relato de tipo descriptivo, para el desarrollo de una ékphrasis; y su argumentación tan completa, debido a la multitud de topoi posibles, iniciaba en la demostración o refutación de las theseis de tipo práctico o teórico.

En repetidas ocasiones dentro del discurso, después de proporcionar una información sucinta, estrictamente un relato, el orador suele desarrollar con mayor detenimiento lo que es más de su interés, ya sea la caracterización del personaje, la descripción de un lugar o la elaboración

\footnotetext{
92 Theo., 95-96.
} 
de una comparación o un discurso. Por lo tanto, el uso del relato que suele hallarse en un escrito es frecuentemente de introducción a otros progymnásmata, es decir, primero se sitúa al oyente proporcionándole todos los elementos necesarios y después se le centra en el detalle de alguno de ellos.

Como hemos visto, a partir de la multitud de topoi posibles bajo los que se puede argumentar una narración, se puede objetar o confirmar cualquier relato, dependiendo de cuál sea el propósito del autor: convencernos o disuadirnos.

También apreciamos que los posibles lugares son innumerables, pues en una narración cualquier elemento que la constituya es un tópico argumentativo en potencia (Cf. Quint., 5, 10).

\section{BIBLIOGRAFÍA}

\section{Fuentes:}

ButTs, J. R., The 'progymnasmata' of Theon, 2 vols., PhD., Ann Arbor, UMI, 1990. Felten, I. (ed.), Nicolaus. Progymnasmata, vol. XI, Lipsiae, Teubner, 1913.

Foerster, R., (ed.), Libanius. Progymnasmata, Opera, vol. VIII, Lipsiae, Teubner, 1915.

García García, M. y GutiérRez Calderón, J., Menandro. Dos tratados de retórica epidíctica, Madrid, Gredos (BCG 225), 1996.

García López, J., Demetrio. Sobre el estilo, Madrid, Gredos (BCG 15), 1996.

NúÑEZ, S., Cicerón. La invención retórica, Madrid, Gredos (BCG 245), 1997.

_., Retórica a Herenio, Madrid, Gredos (BCG 244), 1997.

Patillon, M. y G. Bolognesi (eds.), Aelius Theo, Progymnasmata, Paris, Belles Lettres, 1997.

Rabe, H. (ed.), Aphthonius. Progymnasmata, vol. X, Lipsiae, Teubner, 1926.

_, (ed.), Hermogenes. Progymnasmata, vol. VI, Lipsiae, Teubner, 1913.

_, (ed.), Ioannis Sardiani commentarium in Aphthonii Progymnasmata, Lipsiae, Teubner, 1928.

RaCiOnero, Q., Aristóteles. Retórica, Madrid, Gredos (BCG 142), 1999.

ReCHE, M. D., Teón, Hermógenes, Aftonio. Ejercicios de retórica, Madrid, Gredos (BCG 158), 1991.

Ruíz Montero, C., Hermógenes. Sobre las formas de estilo, Madrid, Gredos (BCG 184), 1993

SÁnchez SAnZ, J., Retórica a Alejandro, Salamanca, Universidad de Salamanca, 1989. 


\section{Estudios:}

AragüÉs Aldaz, J., “Modi locupletandi exempla. Progymnasmata y teorías sobre la dilatación narrativa del exemplum", Euphrosyne, 25, 1997, pp. 415-434.

Cribiore, R., Writing, Teachers and Students in Graeco-Roman Egypt, Atlanta, Scholars Press, 1996.

FonTANIER, P., Les figures du discours, Paris, Flammarion, 1977.

Genette, G., "Fronteras del relato", en AA.vv., Análisis estructural del relato, Buenos Aires, Tiempo Contemporáneo, 1970, pp. 193-208.

GUERrini, R., "Tipologia di 'fatti e detti memorabili': dalla storia all'exemplum", MD, 4, 1980, 77-96 (=en Studi su Valerio Massimo, Pisa, Giardini, 1981, pp. 11-28).

Hock, R. F. y O'NeIL, E. N., The Chreia and Ancient Rhetoric. Classroom Exercises, Leiden, Scholars Press, 2002.

KrIEL, D. M., "The Forms of the sententia in Quintilian VIII, 5, 3-24”, AClass, 4, 1961, pp. 80-89.

Malosse, P. L., "La pratique concrète de l'amplification dans la rhétorique ancienne: l'exemple de Libanios dans son éloge des empereurs Constance et Constant", RP, 74, 2000, pp. 179-197.

Meijering, R., Literary and Rhetorical Theories in Greek Scholia, Groningen, Forsten, 1987.

O'BANION, J. D., "Narration and Argumentation: Quintilian on Narration as the Heart of Rhetorical Thinking", Rhetorica, 5, 1987, pp. 325-351.

RABAU, S., "Narration et description: l'exigence de détails", Lalies, 15, 1995, pp. 273-289.

RAPP, C., "Storytelling as Spiritual Communication in Early Greek Hagiography: The Use of Diegesis", JECS, 6, 1998, pp. 442-443.

Schouler, B., La tradition hellénique chez Libanios, 2 vols., Paris, Belles Lettres, 1984. 